\title{
Second Screen: User Behaviour of Spectators while Watching Football
}

\author{
By Florian Pfeffel \\ Peter Kexel \\ Christoph A. Kexel \\ Maria Ratz ${ }^{+}$
}

The popularity of parallel media usage has increased in Germany recently. Second Screen describes the use of a second device by television viewers to consume further content which is related to the programme they are watching. The research objective of this study was to reveal insights into the media consumption and user behaviour of football spectators regarding Second Screen services. The survey, which was conducted among German football supporters, showed that their parallel media usage was lower while a football match was broadcasted compared to other TV programmes. However, if supporters used a second device, while watching football, they were using specific Second Screen services more often. Furthermore, it was found that football supporters are particularly interested in "functional" services such as statistics and less into social or even gaming activities. Often more than one Second Screen service is used while a match is broadcasted.

Keywords: Media Consumption, Second Screen, Sport Marketing, Sport Spectator Behaviour, User Behaviour.

\section{Introduction}

The popularity of smartphones and tablets increased enormously since 2011 due to technological advances in the communication markets (BVDW et al. 2014). For example, it was found in a study from the Bundesverband Digitale Wirtschaft (BVDW) in cooperation with Google and TNS Infratest that $60 \%$ of the male and $48 \%$ of the female participants were using online services more often since they had a smartphone. Moreover, people are now online constantly in various situations and not only when they are using their PC or laptop. In fact, the parallel media usage has increased rapidly with the recent technological development. In general, up to $70 \%$ of smartphone and tablet owners use their device, while watching TV (Odijk et al. 2013). A study by the German public broadcasters ZDF and ARD (Busemann and Tippelt 2014) found that 2014 approximately $57 \%$ of web affine people were using a

\footnotetext{
* Professor, accadis Hochschule Bad Homburg - University of Applied Sciences, Germany.

${ }^{\dagger}$ Lecturer, accadis Hochschule Bad Homburg - University of Applied Sciences, Germany.

* Doctor, Executive Board and Lecturer, accadis Hochschule Bad Homburg - University of Applied Sciences, Germany.

+ Research Assistant, accadis Hochschule Bad Homburg - University of Applied Sciences, Germany.
} 
second device such as a tablet or smartphone to be online while watching TV $34 \%$ of those are running online activities on the second device, which are directly linked to the actual TV programme, which can be described as Second Screen (Busemann and Tippelt 2014).

Second Screen services have been developed in special settings as well. For example, in relation to football broadcasting in Germany the professional football clubs or the football association, broadcasters and other service providers, started to engage in this technological advances in recent years. Second Screen services in the context of sport broadcasting provide additional statistical match data further information regarding the players. Almost every club in the $1^{\text {st }}$ Bundesliga have particular apps or at least sections on their website which are specifically designed to provide fans and other stakeholders with additional information such as statistics, live ticker and live tables during a match. The broadcasters, for instance the public ones ARD and ZDF, have very complex services on their online platforms. During the FIFA Football World Cup 2014 they offered different camera perspectives to choose from in their web performance (Busemann and Tippelt 2014). There are even other players who deliver Second Screen services in the context of sport broadcastings. Some (sport) information platforms and newspapers such as Kicker, Sport1 and BILD have very common services, which are popular among football spectators. Again the motivation behind is to increase the participation of the customers with the platform or service provider by offering interactive features. The dominant teams such as Borussia Dortmund are investing into Second Screen services as they see enormous potential in the online market. They try to enlarge the match atmosphere regarding time (more than 90 minutes) and regarding the location as not only spectators in the stadium should feel the atmosphere, but also fans worldwide. Special merchandise offers should be included in those Second Screen services in relation to scenes that happen on the field (Eisenbrand 2014). Therefore, this paper should reveal more insights into the user behaviour of football spectators who are using Second Screen services, while watching a match on TV by looking at the existing literature briefly in the next paragraph before moving onwards to the research questions, methodology and the initial results of this long-term research project.

\section{Theoretical Background}

Second Screen is still a very young phenomenon and the literature in this area is limited. This is caused by the rapid growth of this technological trend as well as by the fact that the usage of Second Screen services is more considered by practitioners of media organisations than by business researchers. However, empirical data on the user behaviour could deliver important aspects and implications for the practice and therefore it might be worth to conduct more research on this area. 
Existing research, which is strongly linked to Second Screen, investigates interactive TV (iTV) features and user preferences regarding this technology. Findings of those studies were important for the development of the Second Screen applications and showed that people are willing to use interactive functions while watching TV to a certain extent, but that there are still concerns regarding safety and data protection. Furthermore, participants demanded the interactive possibilities in a quick and easy way, without taking away the attention from the main viewing experience. In conclusion, it was found that it was more appreciated by the participants to have a second device for related content and that they did not want to have this information on the TV screen (Cruickshank et al. 2007). With the development of mobile devices, the media behaviour of people changed more and more as users do not only bridge the TV advertisement by using their smartphone, but use it as a second device constantly, while watching TV (Flyacts 2014).

There is no common definition of Second Screen in detail, but a Report by Technologia (Klein et al. 2014) defined it as the "use of handheld devices such as smartphones and tablets in close connection with TV watching". Additional research has been done on tablet users and how they combine multiple media in recent years. The study by Flyacts (2014) reported that the most activities on the second device were not linked to the actual programme. In their analysis only $10 \%$ of the participants used the tablet or smartphone to react to the current TV program. In contrast, they found that $49 \%$ surfed the internet and $47 \%$ checked their e-mails, while watching TV. Courtois and D'heer (2012) stated that the main purposes why people used their tablet, while watching TV, were information and social networking activities. Many studies included those parallel usage activities as well in their study and did not only limit the focus on Second Screen as it would be suggested by the definition in order to receive comparable data. These findings support one classification which has been done by the German broadcasters ARD and ZDF (Busemann and Tippelt 2014). They found that there are three motives that drive people to use Second Screen services: the functional motive (receiving additional information), the social motive (communicating with others) and the gaming motive (votings). The Report by Technologia (Klein et al. 2014) also highlighted the motivation of broadcasters and other players to engage in Second Screen services. For most of them Second Screen is regarded as a new possibility to differentiate the own service and finally, to create additional revenues. But in order to do so, Wilson (2016) argued that a nuanced understanding of the viewing habits is necessary which addresses especially the audience pleasures or even displeasures in Second Screen usage. These business motivations and the need to investigate the user behaviour in more detail, provides the rationale for further research in this area. 


\section{Research Objectives and Methodology}

As mentioned above there are some general studies regarding the use of Second Screen services as well as the motivations of broadcasters to develop those services and the motives why people might use them. However, the authors could not find any empirical data on Second Screen in special contexts such as sports and in particular football broadcasting. For the practical implementation of further Second Screen services a detailed understanding of the user behaviour is necessary. Therefore, the research questions for this paper are: To which extent do football fans use Second Screen services, while watching a match on TV compared to other TV programme and what services are they asking for? The research objective is to support sport organisations with future sport marketing decisions regarding the implementation and extension of Second Screen services.

In order to test the existing studies on Second Screen services in the context of football clubs, the research design is based on a quantitative approach. Within the overall project, a survey was conducted in cooperation with a German football club in the Rhine-Main area in Germany in 2015. The questionnaire was distributed randomly by using the online communication channels of the club. The questionnaire consists of 37 questions in total within six sections regarding demographical data, identification with the club, online behaviour while watching TV, while watching football, as well as in the stadium and the specific personal preferences regarding online services. Some of the questions (especially regarding the parallel and Second Screen usage) were adopted from the study by Busemann and Tippelt (2014) in order to allow a comparison of the results. The survey took part in two steps, firstly with a large online survey with approximately 1,400 participants and secondly with a smaller offline survey at a match day in the stadium. By comparing the data from both sets distortions by just asking online users could be avoided. The sample size is representative in accordance with the population given a confidence level of $99 \%$ and a margin of error of $3 \%$.

For this paper especially those questions were examined in more detail which dealt with the content and preferences of the Second Screen services, which the spectators were using.

\section{Results}

Figure 1 summarises the comparison of the parallel media usage and Second Screen behaviour of football spectators, while watching TV in general and while watching a football match. The research showed that there are differences between the Second Screen behaviour of football fans while they are watching TV in general and while a football match is broadcasted. 
Figure 1. Parallel and Second Screen User Behaviour while Watching TV In General and while Watching Football

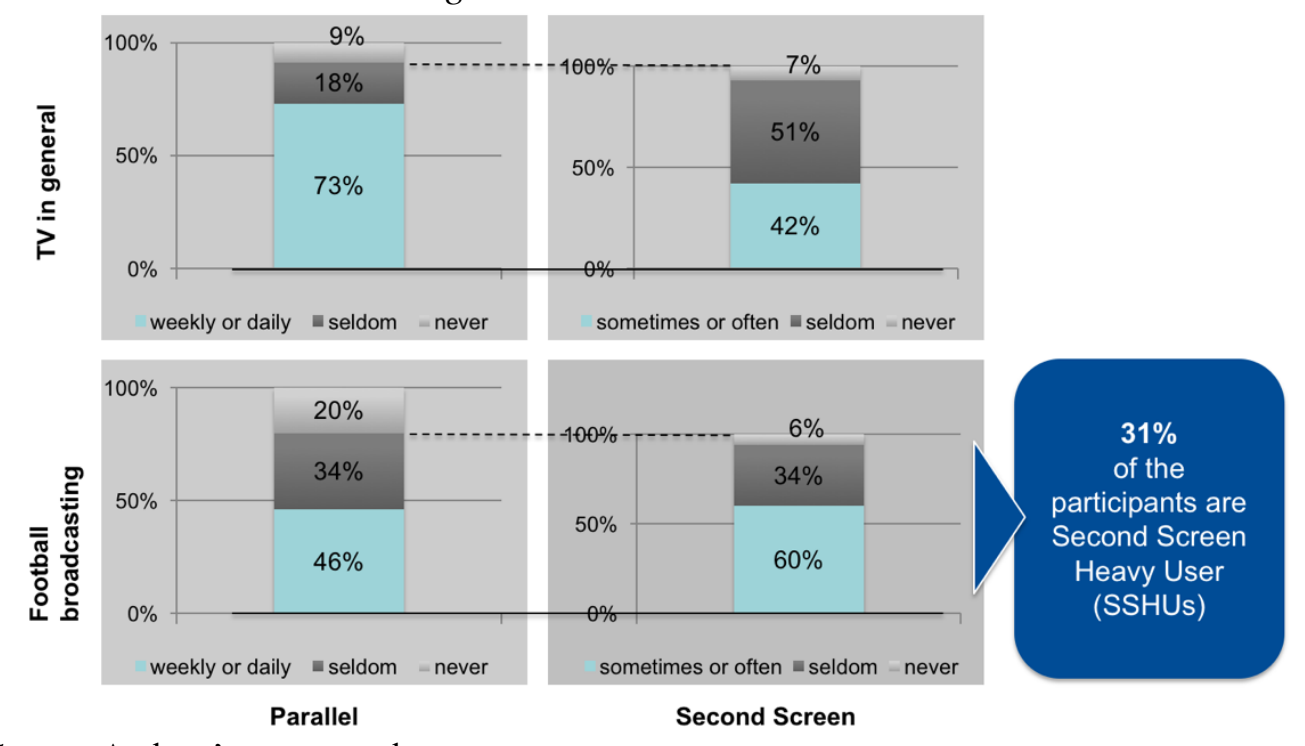

Source: Authors' survey results.

The majority (73\%) used a second device on a daily or weekly basis, while watching TV in general. In relation to Second Screen $42 \%$ of the participants stated that they used content related service mostly or often, while watching TV. Comparing this to the study from ARD und ZDF with $32 \%$ of Second Screen users (Busemann and Tippelt 2014), football spectators seem to have a higher Second Screen usage in general. Live football of the $1^{\text {st }}$ Bundesliga in Germany is broadcasted by the pay TV provider Sky. Only $46 \%$ of the participants used a second device, while they were watching a football match. If participants used a second device in the particular setting, the online activities were much more related to the actual football broadcasting on the $\mathrm{TV}$, because $60 \%$ of the participants used content which was related to the football match "mostly" or "often". In conclusion these results stated that football supporters have a lower parallel media usage, while watching a football match but with a higher correlation between the content on the TV and the second device (both the football matches). This finding might be obvious as the particular target group of football fans is certainly more interested in football broadcastings as in the normal TV programme (consisting of quiz or cooking show) and the latter does not require such a high attention for them (Pfeffel et al. 2016a). In general words this finding could suggest that people use Second Screen only intensively for those broadcastings which they are really interested in and where they want to receive more information. Their parallel usage is lower in those cases than usual as they spend their attention only to the special broadcasting. They have a higher parallel usage (for example surfing the internet, without relation to the TV programme) only in other contexts where a high attention is not required. This assumption is proven by the earlier mentioned studies on interactive TV (Tsekleves et al. 2007) and will be tested in future research with other settings. 
Within the analysis a group of people was identified who are parallel media users on a daily or weekly basis, while watching football and they used content related online services with that parallel device mostly or often (in this case content which is related to the football broadcasting). They are called Second Screen Heavy Users (SSHUs) and made up 31\% of the participants. The demographic characteristics were analysed in particular for the SSHUs. However, no significant differences where found regarding the gender as $31.1 \%$ were male and $30.7 \%$ were female. Other personal characteristics as well as demographic correlations are presented within other parts of this longterm research project (Pfeffel et al. 2016b).

In order to address future sport marketing decisions, another focus of the data analysis in this paper was on the online activities which were of particular interest for the target group, while watching a football match on the TV. The preferred Second Screen services are statistics and live ticker, which both were named by more than $70 \%$ of the SSHUs (multiple responses were allowed). Football supporters were also interested in participation possibilities like commenting on social networks such as Twitter and Facebook (31\%). Only few participants took part in online voting $(9 \%)$ or ask questions to experts $(1 \%)$. These preferences are shown in Figure 2.

Figure 2. Activities of SSHUs while Watching Football

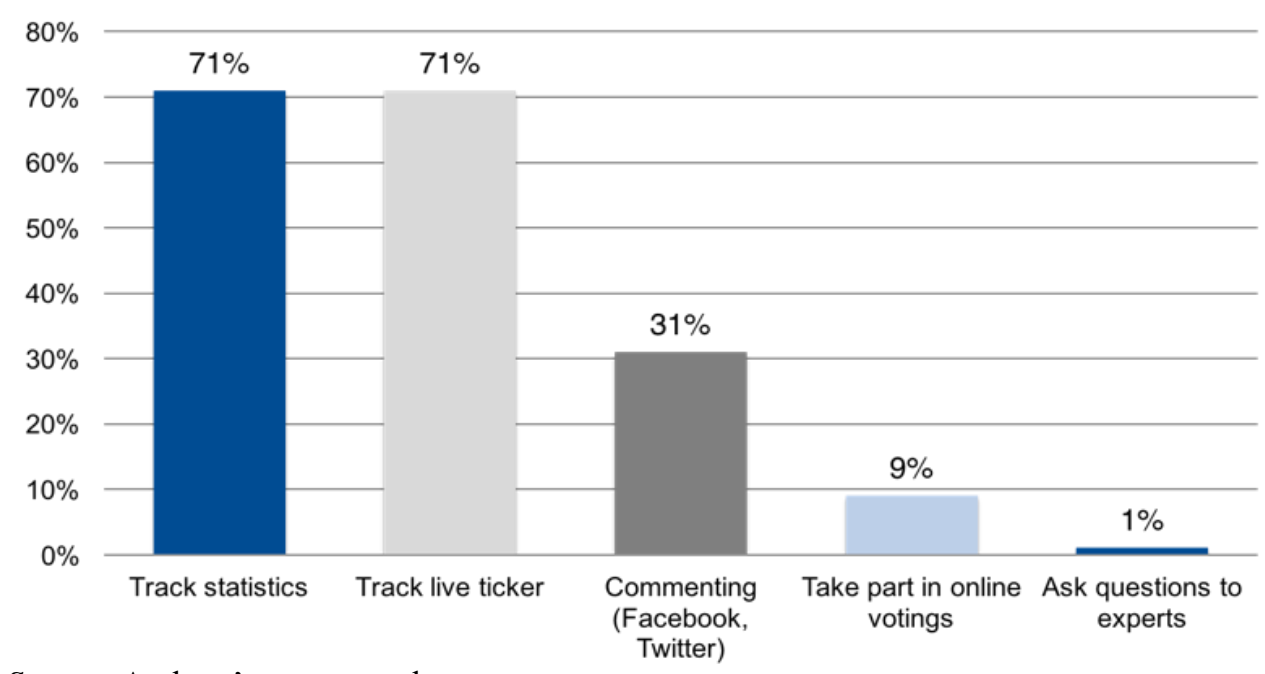

Source: Authors' survey results.

Transferring the classification from the study conducted by the German public broadcasters ARD and ZDF (Busemann and Tippelt 2014) the application area "Functional" would be the most preferred category of Second Screen services in comparison to "Social" and "Gaming" by football spectators as seen in Figure 3. Interacting with others in that respect seems to be a minor motivation behind the Second Screen usage, whereas gaming opportunities does not attract the attention of the participants to a significant extent. Participants could rank their answers from 1 (no interest at all) to 5 (very interested). 
Figure 3. Classification of Activities by the SSHUs while Watching Football

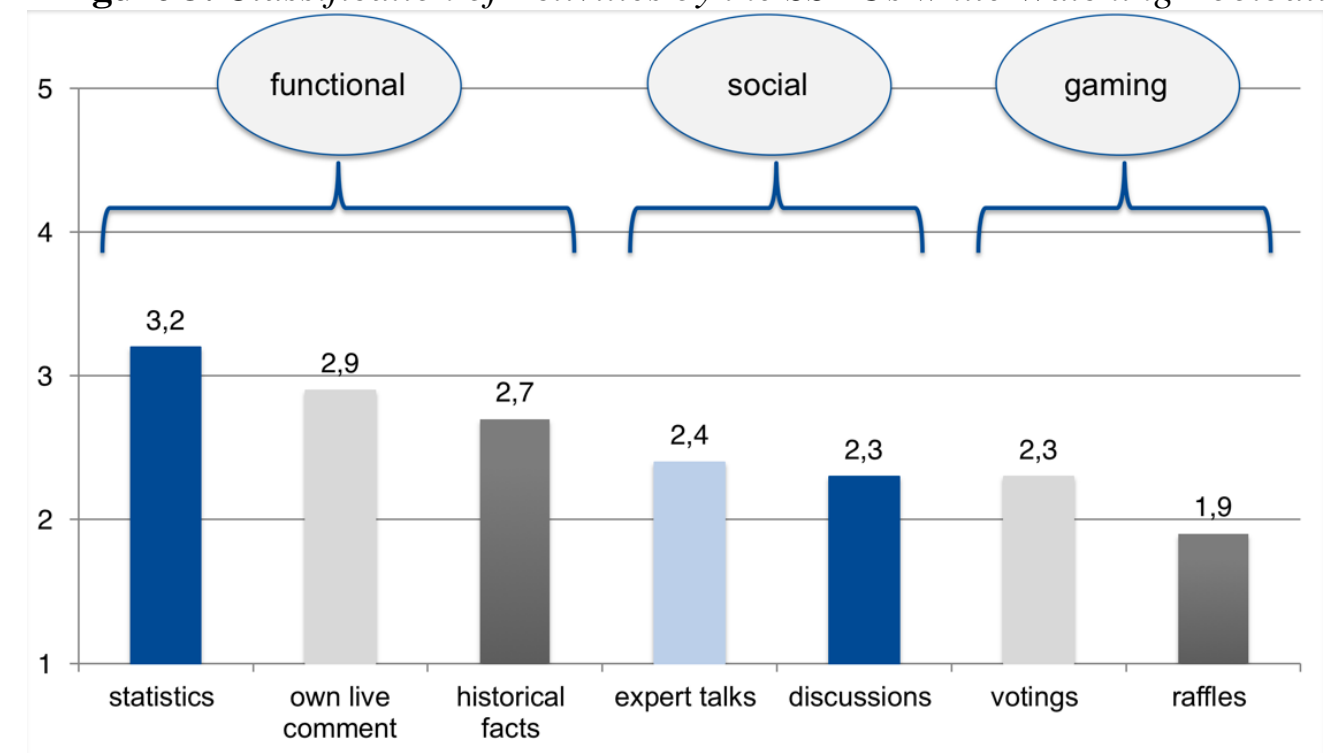

Source: Authors' survey results.

By now no significant and reliable results were found regarding the kind of statistics which are demanded most by the spectators. Different factors such as ball possession, goal kicks, foul and duel statistics are available and used frequently, without a specific ranking. Recently, some organisations are developing and promoting own aggregated Figures which combines those different statistical factors to one number. This application seems to be appropriate for Second Screen users especially for smartphone users owing to display size. The statistic supplier for the DFL (German Football League), Opta, has an own app called 442 Stats Zone with the so called player influence indicator about the overall performance of a player (Haymarket Media Group 2016). Some clubs have own statistical performance indicators or evaluations for their players on their website.

Moreover, it was found that most of the football supporters are using more than one app or online service, while watching TV as it is shown in Figure 4. There are various apps from magazines and newspapers (for example Kicker or Bild) and other providers, which are used more often than those services which are directly linked to a particular club. Only $27 \%$ of the supporters used the live ticker within the club-owned app, while watching the match (the second icon in the diagram). In comparison, the app from Kicker (the first icon in the diagram) was used by $64 \%$ of the participants. Kicker is one of the major sport information platforms in Germany and within the app there are numerous Second Screen features such as statistics, background information and interactive possibilities like a management game. 
Figure 4. Applications which are Used for Second Screen Services

\section{Channels}

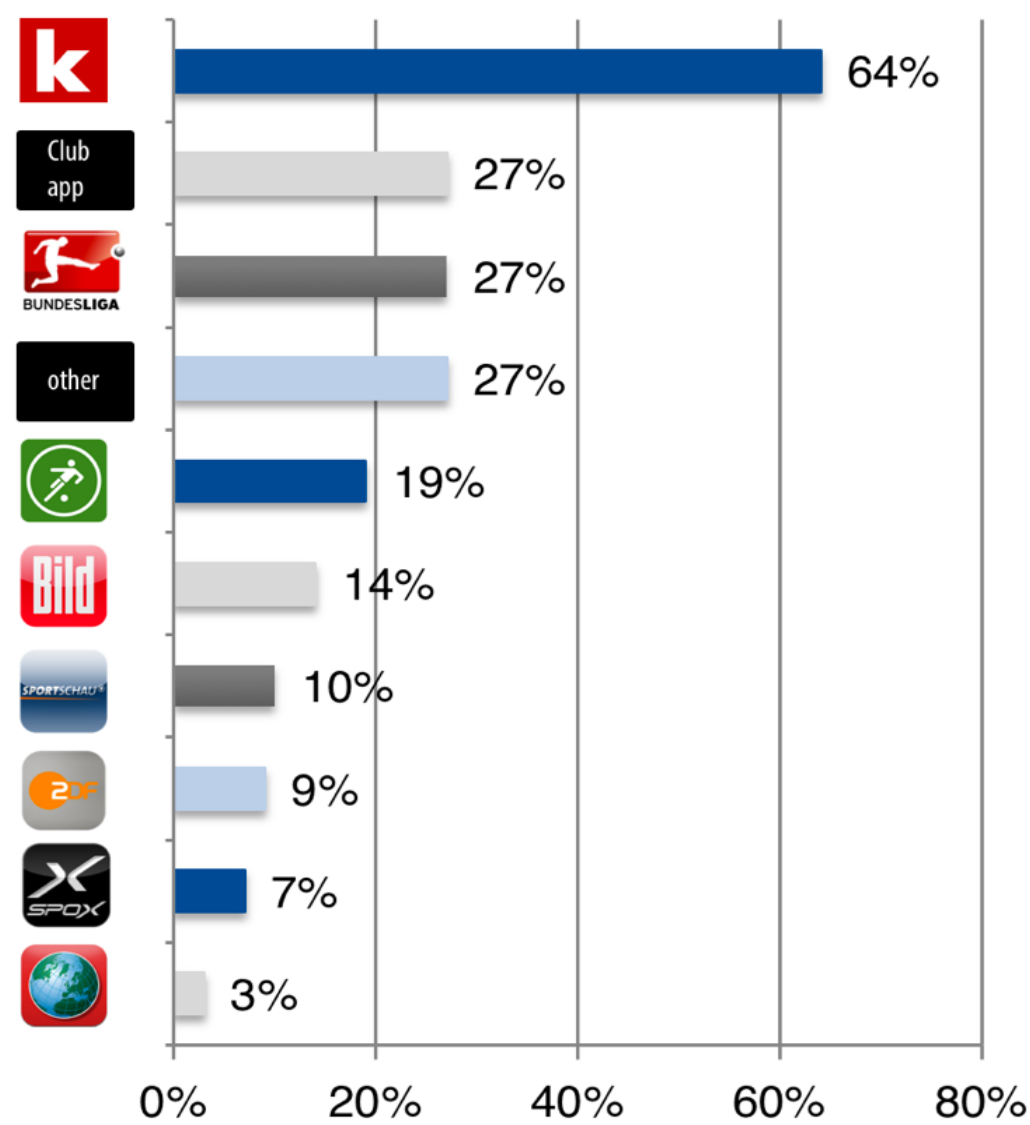

Source: Authors' survey results.

\section{Conclusion and Future Research}

This paper investigated the media behaviour in relation to Second Screen of football spectators with particular interest into those activities which are used most by the participants. It was found that most football spectators are much more interested in functional information such as statistics and facts as in social or gaming features.

In conclusion, the results are not completely comparable to those of the study by the German broadcasters ARD and ZDF (Busemann and Tippelt 2014) regarding the extent to which Second Screen services are used although the same key questions were used. The Second Screen usage of the football spectators which took part in this study is quite higher. Whether this finding is based on the particular context of sport or football will be tested in future research by using the same questionnaire for other football clubs or even other sports settings. With this ongoing research comparable data will be collected in order to test whether fans of other clubs have the same preferences and media behaviour. In accordance with Figure 4 the club specific Second Screen 
services are not the most popular ones used by the football fans which imply that the user behaviour should be quite similar among the population of football fans. However, this random sampling among fans of only one football club could be a limitation of this study.

As Second Screen is still an emerging technological trend, there are continuously new developments by the players in that markets which needs to be observed and evaluated. The findings of this paper as well as further research could give important management implications to the football clubs in order to improve their Second Screen services. Whether it is possible to use these new opportunities to generate an economic return need to be analysed in future research.

\section{References}

Busemann K, Tippelt F (2014) Second screen: Parallelnutzung von Fernsehen und Internet - Ergebnisse der ARD/ZDF-Onlinestudie 2014 [Second screen: parallel use of television and internet - results of the ARD/ZDF online study]. Media Perspektiven. 7-8: 408-416. Retrieved from http://goo.gl/uQAZ71.

BVDW, Google, TNS (2014) Faszination mobile. Verbreitung, nutzungsmuster und trends - bundesverband digitale wirtschaft in kooperation mit Google und TNS infratest. [Fascination mobile. Distribution, usage patterns and trends - BVDW in cooperation with Google and TNS Infratest]. Retrived from http://goo.gl/ UAofQN.

Courtois C, D'heer E (2012) Second screen applications and tablet users: constellation, awareness, experience, and interest. EuroiTV'12 Proceedings of the 10th European conference on Interactive TV and Video: 153-156.

Cruickshank L, Tsekleves E, Whitham R, Hill A and Kondo K (2007) Making interactive TV easier to use: interface design for a second screen approach. The Design Journal: An International Journal for All Aspects of Design 10(3): 41-53.

Eisenbrand R (2014) Digital können wir das Stadionerlebnis auf 840 Minuten verlängern [We can extend the stadium experience at 840 minutes digital]. Online Marketing Rockstars. Retrieved from http://goo.gl/EG8eTK.

Flyacts GmbH (2014) Die Rolle von Apps in der Second- \& Multi-Screen-Nutzung [The role of apps in the second- and multi-screen use]. Retrieved from http://goo. $\mathrm{gl} / 2 \mathrm{GWQvL}$.

Haymarket Media Group (2016). FourFourTwo - Stats Zone. Retrieved from http://goo.gl/V3tlQF.

Klein J, Freeman J, Harding D, Teffahi A (2014) Assessing the impact of second screen. Report by Technologia in Association with DTG and I2 Media Research MC/168: 1-179. Retrieved from http://goo.gl/prLPdd.

Odijk D, Meij E, de Rijke M (2013) Feeding the second screen: semantic linking based on subtitles. OAIR. Retrieved from https://goo.gl/Asa0aw.

Pfeffel F, Kexel P, Imschweiler I, Kexel C.A (2016a). Wenn Zuschauen alleine nicht mehr reicht - über den parallelen Medienkonsum im Sport. [If watching TV is not enough anymore - about the parallel media consumption in sport]. accadis denkpunkt 1(1): 6-13.

Pfeffel F, Kexel P, Kexel CA, Ratz M (2016b) Second screen: watching football on tv is not enough. Abstract and Oral Presentation on the 18th International 
Conference on Sport Management and Marketing. Proceedings not yet published. Internal Document.

Tsekleves E, Cruickshank L, Hill A, Kondo K, Whitham R (2007). Interacting with digital media at home via a second screen. Proceedings of the Ninth IEEE International Symposium on Multimedia Workshops: 201-207.

Wilson S (2016) In the living room: second screens and TV audiences. Television \& New Media 17(2): 174-191. 